\title{
Fitossociologia do estrato arbustivo-arbóreo em regeneração em área de Caatinga, Baixio-CE
}

\author{
Eliane Gomes de Lima²; Veralucia Santos Barbosa ${ }^{3}$
}

\begin{abstract}
Resumo: A Caatinga é um dos ecossistemas ambientalmente mais degradado e menos conhecido no que se refere à dinâmica da vegetação e dos processos ecológicos ocorrentes. Com o objetivo de determinar a composição florística e estrutura da comunidade vegetal, em um fragmento de Caatinga em regeneração, este trabalho foi desenvolvido em uma área de depressão sertaneja, localizada na comunidade do Sítio Cigano, Baixio-CE. As coletas de dados foram realizadas em três gradientes de distância, iniciando na borda e indo em direção ao interior da floresta. Para cada gradiente, foram demarcadas três parcelas fixas de $10 \mathrm{~m}$ x $10 \mathrm{~m}$, sendo incluídos todos os indivíduos de espécies arbustivo-arbóreas com CAP (circunferência à altura do peito) $\geq 10 \mathrm{~cm}$ e altura $\geq 1,5 \mathrm{~m}$. Foram amostrados 64 indivíduos, distribuídos em quatro famílias, cinco gêneros e cinco espécies para o gradiente I; 77 indivíduos distribuídos em quatro famílias, oito gêneros e oito espécies para o gradiente II; e 49 indivíduos distribuídos em nove famílias, 13 gêneros e 13 espécies para o gradiente III. Fabaceae foi a família com maior riqueza e abundância de espécies nos três gradientes. As espécies mais abundantes e com maior valor de importância foram: Croton sp. para o gradiente I, Bauhinia cheilantha (Bong.) Steud. para o gradiente II e Poincianella pyramidalis (Tul.) L. P para o gradiente III. Registrou-se maior diversidade para o gradiente III. O predomínio de espécies secundárias iniciais em toda a área indica uma regeneração lenta.
\end{abstract}

Palavras - chave: Vegetação; Fragmentação; Depressão sertaneja.

\section{Phytosociology of the stratum the woody regenerating in Caatinga area, Baixio- CE}

\begin{abstract}
The Caatinga is one of the most degraded ecosystems from an environmental point of view and the least known with regard to the dynamics of vegetation and ecological processes that occur. With the objective of determining the floristic composition and structure of the plant community in a regenerating Caatinga fragment, this work was developed in backlands depression area, located in the community of Sítio Cigano, Baixio-CE. The data collections were carried out in three distance gradients, starting at the edge and going towards the interior of the forest. They were plotted three fixed plots of $10 \mathrm{~m} \times 10 \mathrm{~m}$ for each gradient and included all individuals of shrub-arboreal species with CAP (circumference at breast height) $\geq 10 \mathrm{~cm}$ and height $\geq 1,5 \mathrm{~m} .64$ individuals were sampled distributed in four families, five genera and five species for the I gradient; 77 individuals in four families, eight genera and eight species to the II gradient; and 49 individuals distributed nine families, 13 genera and 13 species for III gradient. Fabaceae was the family with greater wealth and abundance of species in the three gradients. The most abundant species with largest importance value were Croton $\mathrm{sp}$. for the I gradient, Bauhinia cheilantha (Bong.) Steud. for the II gradient and Poincianella pyramidalis (Tul.) L. P for the III gradient. It was registered a greater diversity to the III gradient. The predominance of initial secondary species in the whole area indicates a slow regeneration.
\end{abstract}

Keywords: Vegetation; Fragmentation; Backlands depression.

\footnotetext{
${ }^{1}$ Recebido em 27.06.2018 e aceito para publicação como artigo científico em 13.09.2018.

2 Bióloga, Pós-graduanda em Docência do Ensino Superior pela Universidade Federal de Campina Grande (UFCG). E-mail: <elianybio@gmail.com>

${ }^{3}$ Bióloga, Dra. Professora Adjunta IV da Universidade Federal de Campina Grande (UFCG). E-mail: <veraluciasb@yahoo.com.br>
} 


\section{Introdução}

Apresentando tipologias vegetais bastante variadas, as quais são decorrentes de mecanismos adaptativos e condicionadas pelo clima local (SANTANA e SOUTO, 2006; CALIXTO JÚNIOR e DRUMOND, 2011), a Caatinga abrange cerca de $900 \mathrm{mil} \mathrm{km}$, correspondendo a aproximadamente $54 \%$ da região Nordeste e $11 \%$ do território brasileiro. Ocorre em áreas pertencentes aos estados do Ceará, Rio Grande do Norte, Paraíba, Pernambuco, Alagoas, Sergipe, Piauí, Bahia e Minas Gerais (ANDRADE et al., 2005).

Caracterizada como formações arbóreoarbustivas, hierarquizadas em diversas tipologias vegetais (PEREIRA et al., 2001), a vegetação da Caatinga, segundo Giulietti et al. (2003), apresenta como características básicas: cobrir uma área mais ou menos contínua submetida a um clima semiárido e bordeado por clima úmido; apresentar espécies com adaptações à deficiência hídrica - caducifolia, herbáceas anuais, suculência, acúleos e espinhos, predominância de arbustos e árvores de pequeno porte, cobertura descontínua de copas - e espécies endêmicas. No entanto, esta região ainda é pouco conhecida, principalmente no que se refere a sua dinâmica biológica (PEREIRA et al., 2001; SANTANA e SOUTO, 2006), permanecendo como um dos ecossistemas cientificamente menos conhecidos da América do Sul (TABARELLI e SILVA, 2003).

Andrade et al. (2007) enfatizam que este ecossistema tem sido historicamente devastado para ceder lugar a atividades agropecuárias. De fato, Drumond et al. (2000) afirmam que, como resultado da interferência humana, mais de $80 \%$ da vegetação da Caatinga são sucessionais, cerca de $40 \%$ são mantidas em estado pioneiro de sucessão secundária e, a desertificação já se faz presente em aproximadamente $15 \%$ da área. Após a perturbação, essas áreas são abandonadas dando início ao processo de sucessão ecológica, o qual muitas vezes é interrompido por novas intervenções; assim, a vegetação da Caatinga apresenta-se como um mosaico formado por variados estágios serais, resultantes dos usos ali imputados (ANDRADE et al., 2007).

As respostas das comunidades vegetais e de cada espécie à fragmentação variam de acordo com o histórico do fragmento, seu tamanho e forma, impactos das ações humanas atuais, grau de isolamento e a sensibilidade da comunidade e dos indivíduos de cada espécie a estes processos (RAMBALDI e OLIVEIRA, 2003). Logo, conhecer a distribuição dos organismos e das comunidades é primordial para a preservação da diversidade biológica, bem como para quantificar os efeitos da ação antrópica (TABARELLI e VICENTE, 2003). Assim, compreender a dinâmica dos processos de regeneração natural e sucessão ecológica na Caatinga é de suma importância, para o estabelecimento de ações de recuperação de áreas degradadas, bem como o desenvolvimento de um manejo sustentável dos recursos florestais neste ecossistema.

Nesse contexto, a fitossociologia se torna uma importante ferramenta em estudos desta natureza, os quais apresentam máxima relevância para a caracterização do papel exercido por cada espécie dentro da fitocenose, além de contribuírem, de forma decisiva, na indicação dos estágios sucessionais e na melhor avaliação da influência de fatores de clima, solo e ação antrópica nas comunidades vegetais (CABRAL et al., 2013).

Embora existam registros de estudos fitossociológicos realizados na Caatinga (RODAL et al., 1998; NASCIMENTO, 1998; ALCOFORADO-FILHO et al., 2003; CABRAL, 2014), ainda falta muito para o conhecimento deste ecossistema como um todo, havendo a necessidade de levantamentos das espécies, definindo seus padrões de abundância e distribuição geográfica e suas relações com fatores ambientais (RODAL, 1992). No que se refere aos estudos fitossociológicos em áreas perturbadas estes são ainda mais escassos, ocorrendo em sua maioria no estado da Paraíba (ANDRADE et al., 2007; ANDRADE et al., 2005; FABRICANTE e ANDRADE, 2007; ARAÚJO et al., 2012; DANTAS et al., 2010).

Diante do exposto, o presente estudo teve 
como objetivo determinar a composição florística e a estrutura fitossociológica da comunidade vegetal, em diferentes gradientes de distância, em área de Caatinga sob regeneração natural, na comunidade do Sítio Cigano, no município de Baixio-CE.

\section{Material e métodos}

Área de estudo

O estudo foi realizado em um fragmento de Caatinga com 1,27 ha, o qual se encontra em processo de regeneração natural há aproximadamente 30 anos, localizado no Sítio Cigano, Zona Rural do Município de Baixio, no estado do Ceará $\left(6^{\circ} 43^{\prime} 48^{\prime \prime}\right.$ S 38 $38^{\circ}$ '01' W). O mesmo foi utilizado como área de cultivo, tendo sido abandonado posteriormente, passando a ser usado apenas para pastagem de bovinos. Segundo classificação da EMBRAPA (2006), a região apresenta solos do tipo Luvissolos e Neossolos. De acordo com dados do IPECE (2014), o relevo é caracterizado como depressão sertaneja, a vegetação existente é Caatinga Arbustiva Densa e Floresta Caducifólia Espinhosa. O clima predominante é Tropical quente semiárido com temperaturas médias variando de $26^{\circ} \mathrm{C}$ a $28^{\circ} \mathrm{C}$ e precipitação pluviométrica média de 741,5 $\mathrm{mm} / \mathrm{ano}$, concentrada nos meses de fevereiro a abril (IPECE, 2014).

Coleta de dados

O estudo foi desenvolvido no período de fevereiro a maio de 2016. Foram delimitadas nove parcelas fixas de $10 \mathrm{~m} \times 10 \mathrm{~m}$, seguindo metodologia de Durigan (2003) apud Freitas e Magalhães (2012), totalizando uma área amostrada de $900 \quad \mathrm{~m}^{2}$, distribuídas sequencialmente em três gradientes de distância da borda, no decorrer da área em regeneração: gradiente I, localizado a $10 \mathrm{~m}$ da borda do fragmento; gradiente II, a $100 \mathrm{~m}$ do primeiro gradiente; e gradiente III, distando $100 \mathrm{~m}$ do segundo gradiente. Em cada gradiente foram delimitadas três parcelas, onde foram amostrados todos os indivíduos de espécies arbustivo-arbóreas, com altura igual ou superior a $1,5 \mathrm{~m}$ e circunferência à altura do peito - CAP $(1,30 \mathrm{~m}$ do solo) igual ou superior a $10 \mathrm{~cm}$. Os indivíduos que se ramificavam a menos de 1,30 $\mathrm{m}$ do solo tiveram as circunferências das suas ramificações somadas. Indivíduos que se ramificavam à altura do solo, não apresentando uma base comum, tiveram cada perfilho considerado como um indivíduo. Foram adotados os valores de CAP para cálculo da área basal individual de cada planta.

Em campo, para cada gradiente, foram registradas a riqueza e abundância de espécies, também foram feitas observações, para posterior classificação das espécies, quanto ao hábito de crescimento e grupo ecológico sucessional. A classificação quanto ao hábito se deu através de comparações com trabalhos de Rodal et al. (2002), Santana e Souto (2006), Cabral (2014) e Holanda et al. (2015). Quanto ao grupo ecológico, adotou-se identificações apresentadas em estudos de Carvalho (2010), Carvalho et al. (2012) e Calixto Junior e Drumond (2011). Quando houve divergência entre os autores, considerou-se a maior concordância destes. Para categorizar as espécies quanto aos grupos ecológicos que não se encontravam descritas nos trabalhos citados, adotou-se classificação a partir de descrições propostas por Gandolfi et al. (1995).

Amostras de material botânico foram coletadas para posterior identificação, a qual se deu por meio de literatura especializada e consulta a especialistas.

Análise dos dados

Foram calculados, para cada espécie, os seguintes parâmetros fitossociológicos de estrutura horizontal: densidade absoluta, densidade relativa, frequência absoluta, frequência relativa, dominância absoluta, dominância relativa e valor de importância. A descrição de tais parâmetros e suas respectivas fórmulas seguiu a metodologia proposta por Rodal et al. (2013). Os parâmetros foram calculados com o programa FITOPAC 2.1 
(SHEPHERD, 1995).

Para verificação da diversidade foi calculado, para a área total e para cada gradiente, o índice de diversidade de Shannon-Wiener ( $\left.H^{\prime}\right)$. A similaridade entre os três gradientes foi comparada a partir do índice de Jaccard (SJ). O teste de Mann-Whitney (U) foi utilizado para verificar qual gradiente apresentava maior diversidade. A normalidade das variáveis foi verificada através do teste de Lilliefors, todas as análises foram feitas com o software BIOESTAT 5.3 (AYRES et al., 2007).

\section{Resultados e Discussão}

Para os três gradientes de Caatinga estudados, foram amostrados 190 indivíduos pertencentes a 14 espécies arbustivas e arbóreas, distribuídas em nove famílias. Deste total, apenas três espécies, o que corresponde a 21,43\%, são arbustivas. Em relação ao grupo ecológico, foram registradas três espécies pioneiras, seis secundárias iniciais e cinco secundárias tardias, sendo que as duas primeiras categorias corresponderam juntas a $64,29 \%$ das espécies registradas (Tabela 1). Fabaceae foi a família mais representativa em número de espécies, contribuindo com seis espécies. Sendo também, juntamente com Euphorbiaceae, as com maiores quantidades de indivíduos. Outros estudos em diferentes tipologias de Caatinga também apontaram essas famílias como as mais significativas em número de espécies e indivíduos (LEMOS e RODAL, 2002; RODAL e NASCIMENTO, 2002; ALCOFORADOFILHO et al., 2003; ANDRADE et al., 2005; SILVA et al., 2012; MARANGON, 2013; CABRAL, 2014).

Tabela 1 - Famílias e espécies vegetais arbustivo-arbóreas amostradas para a área de Caatinga do Sítio Cigano, Baixio-CE, com seus respectivos nomes populares, hábitos de crescimento e grupo ecológico, em ordem alfabética das famílias.

Table 1 - Families and plant species sampled for the Caatinga area of Sítio Cigano, Baixio-CE, with their popular names, growth habits and successional ecological group, in alphabetical order of the families.

\begin{tabular}{|c|c|c|c|}
\hline Família/Espécie & Nome popular & Hábito & Grupo ecológico \\
\hline $\begin{array}{c}\text { Anacardiaceae } \\
\text { Myracrodruon urundeuva Allemão }\end{array}$ & Aroeira & Árvore & Secundária tardia \\
\hline $\begin{array}{c}\text { Aspidosperma cf. Pyrifolium Mart. } \\
\text { Bixaceae }\end{array}$ & Pereiro & Árvore & Pioneira \\
\hline $\begin{array}{c}\text { Cochlospermum vitifolium (Willd) Spreng } \\
\text { Boraginaceae }\end{array}$ & Pacotê & Árvore & Secundária tardia \\
\hline $\begin{array}{l}\text { Cordia oncocalyx Allemão } \\
\text { Burseraceae }\end{array}$ & Pau-branco & Arbusto & Secundária inicial \\
\hline $\begin{array}{c}\text { Commiphora leptophoeos (Mart.) J.B. Gillett } \\
\text { Combretaceae }\end{array}$ & Imburana & Árvore & Secundária tardia \\
\hline $\begin{array}{c}\text { Combretum leprosum Mart. } \\
\text { Euphorbiaceae }\end{array}$ & Mofumbo & Arbusto & Secundária inicial \\
\hline $\begin{array}{l}\text { Croton sp. } \\
\text { Fabaceae }\end{array}$ & Marmeleiro & Arbusto & Pioneira \\
\hline Amburana cearenses (Allemão) A.C. Sm. & Camaru & Árvore & Secundária tardia \\
\hline Anadenanthera colubrina (Vell.) Brenan & Angico & Árvore & Secundária inicial \\
\hline Bauhinia cheilantha (Bong.) Steud. & Mororó & Árvore & Secundária inicial \\
\hline Libidibia ferrea (Mart. exTul.) L.P. Queiroz & Pau-ferro & Árvore & Secundária inicial \\
\hline Mimosa tenuiflora (Willd.) Poir & Jurema Preta & Árvore & Pioneira \\
\hline $\begin{array}{c}\text { Poincianella pyramidalis (Tul.) L. P. Queiroz } \\
\text { Malvaceae }\end{array}$ & Catingueira & Árvore & Secundária inicial \\
\hline Pseudobombax marginatum (A. St.-Hil.) A. Robyns & Embiratanha & Árvore & Secundária tardia \\
\hline
\end{tabular}


No gradiente I foram amostrados 64 indivíduos, distribuídos em quatro famílias, cinco gêneros e cinco espécies, ocorrendo uma maior abundância de espécies pioneiras $(53,13 \%$ dos indivíduos amostrados). Croton sp. e Poincianella pyramidalis representaram juntas $59,37 \%$ dos indivíduos amostrados (Tabela 2).

Tabela 2 - Parâmetros fitossociológicos para as espécies arbustivo-arbóreas amostradas no gradiente I, na área de Caatinga do Sítio Cigano, Baixio-CE, em ordem decrescente do valor de importância. (NI = número de indivíduos, $\mathrm{DA}=$ densidade absoluta, $\mathrm{DR}=$ densidade relativa, $\mathrm{FA}=$ Frequência absoluta, $\mathrm{FR}=$ frequência relativa, $\mathrm{DoA}=$ dominância absoluta, $\mathrm{DoR}=$ dominância relativa, VI = valor de importância).

Table 2 - Phytosociological parameters for woody species sampled in the gradient I area of Sítio Cigano, Baixio-CE, in decreasing order of importance value. ( $\mathrm{NI}=$ number of subjects, $\mathrm{DA}=$ absolute density, $\mathrm{DR}=$ relative density, FA $=$ Absolute frequency, $\mathrm{RF}=$ relative frequency, $\mathrm{DoA}=$ absolute dominance, $\mathrm{DoR}=$ relative dominance, $\mathrm{VI}=$ importance value $)$.

\begin{tabular}{|c|c|c|c|c|c|c|c|c|}
\hline Espécies & NI & $\begin{array}{c}\text { DA } \\
(\mathbf{N} / \mathbf{h a})\end{array}$ & $\begin{array}{l}\text { DR } \\
(\%)\end{array}$ & $\begin{array}{l}\text { FA } \\
(\%)\end{array}$ & $\begin{array}{l}\text { FR } \\
(\%)\end{array}$ & $\begin{array}{c}\text { DoA } \\
\left(\mathrm{m}^{2} / \mathrm{ha}\right)\end{array}$ & $\begin{array}{l}\text { DoR } \\
(\%)\end{array}$ & VI \\
\hline Croton sp. & 21 & 700,0 & 32,81 & 100 & 23,08 & 1,39 & 35,45 & 91,33 \\
\hline Poincianella pyramidalis & 17 & 567 & 26,56 & 100 & 23,08 & 0,76 & 19,45 & 69,08 \\
\hline Myracrodruon urundeuva & 12 & 400 & 18,75 & 100 & 23,08 & 1,04 & 26,64 & 68,47 \\
\hline Mimosa tenuiflora & 13 & 433 & 20,31 & 100 & 23,08 & 0,62 & 15,76 & 59,15 \\
\hline Pseudobombax marginatum & 1 & 33 & 1,56 & 33,33 & 7,69 & 0,11 & 2,71 & 11,96 \\
\hline Total & 64 & 2133 & 100 & 433,33 & 100 & 3,92 & 100 & 300 \\
\hline
\end{tabular}

Para o gradiente II foram amostrados 77 indivíduos, distribuídos em quatro famílias, oito gêneros e oito espécies. Neste gradiente ocorreu maior abundância de espécies secundárias iniciais (80,52\% dos indivíduos amostrados). Apresentaram maior densidade as espécies Bauhinia cheilantha e Combretum leprosum, correspondendo a $59,74 \%$ dos indivíduos amostrados neste gradiente; estas espécies foram também as mais frequentes, juntamente com Poincianella pyramidalis. Com maiores valores de dominância relativa se destacaram Poincianella pyramidalis e Combretum leprosum $(41,97 \%)$. Os maiores valores de importância foram registrados para as espécies de Bauhinia cheilatha, Combretum leprosum e Poincianella pyramidalis (Tabela 3 ).

No gradiente III, foram amostrados 49 indivíduos, distribuídos em nove famílias, 13 gêneros e 13 espécies. Neste gradiente ocorreu maior abundância de espécies secundárias iniciais $(61,22 \%$ dos indivíduos amostrados). A espécie predominante em número de indivíduos foi Poincianella pyramidalis, representando $32,65 \%$ dos indivíduos amostrados, seguida de Bauhinia cheilantha e Croton sp.. A espécie com maior frequência relativa foi Poincianella pyramidalis. Os maiores valores de dominância relativa foram registrados para as espécies de Poincianella pyramidalis, Comiphora leptophloeos e Cochlospermum vitifolium. A espécie com maior valor de importância foi a Poincianella pyramidalis (Tabela 4).

Das 14 espécies amostradas, quatro foram comuns aos três gradientes, Poincianella pyramidalis, Mimosa tenuiflora, Croton sp. e Myracrodruon urundeuva. Sendo que dessas quatro espécies, Poincianella pyramidalis foi a que apresentou maiores densidades e valores significativos de importância nas três áreas (69.08, 65.48, 89.71, respectivamente). 
Tabela 3 - Parâmetros fitossociológicos para as espécies arbustivo-arbóreas amostradas no gradiente II, na área de Caatinga do Sítio Cigano, Baixio-CE, em ordem decrescente do valor de importância. (NI = número de indivíduos, DA = densidade absoluta, $\mathrm{DR}=$ densidade relativa, $\mathrm{FA}=$ Frequência absoluta, $\mathrm{FR}=$ frequência relativa, DoA $=$ dominância absoluta, $\mathrm{DoR}=$ dominância relativa, VI = valor de importância).

Table 3 - Phytosociological parameters for woody species sampled in the gradient II area of Sítio Cigano, Baixio-CE, in decreasing order of importance value. ( NI = number of subjects, DA = absolute density, DR = relative density, FA = Absolute frequency, $\mathrm{RF}=$ relative frequency, $\mathrm{DoA}=$ absolute dominance, $\mathrm{DoR}=$ relative dominance, $\mathrm{VI}=$ importance value $)$.

\begin{tabular}{ccccccccc}
\hline Espécies & NI & $\begin{array}{c}\text { DA } \\
(\mathbf{N} / \mathbf{h a})\end{array}$ & $\begin{array}{c}\text { DR } \\
(\boldsymbol{\%})\end{array}$ & $\begin{array}{c}\text { FA } \\
(\boldsymbol{\%})\end{array}$ & $\begin{array}{c}\text { FR } \\
(\mathbf{\%})\end{array}$ & $\begin{array}{c}\text { DoA } \\
\left(\mathbf{m}^{2} / \mathbf{h a}\right)\end{array}$ & $\begin{array}{c}\text { DoR } \\
(\boldsymbol{\%})\end{array}$ & VI \\
\hline Bauhinia cheilantha & 25 & 833 & 32,47 & 100 & 16,67 & 1,18 & 16,34 & 65,48 \\
Combretum leprosum & 21 & 700 & 27,27 & 100 & 16,67 & 1,45 & 20,19 & 64,13 \\
Poincianella pyramidalis & 14 & 467 & 18,18 & 100 & 16,67 & 1,57 & 21,78 & 56,63 \\
Mimosa tenuiflora & 7 & 233 & 9,09 & 100 & 16,67 & 0,57 & 7,98 & 33,74 \\
Croton sp. & 7 & 233 & 9,09 & 100 & 16,67 & 0,31 & 4,34 & 30,10 \\
Anadenanthera colubrina & 1 & 33 & 1,30 & 33,33 & 5,56 & 1,34 & 18,57 & 25,42 \\
Myracrodruon urundeuva & 1 & 33 & 1,30 & 33,33 & 5,56 & 0,64 & 8,84 & 15,70 \\
Libidibia ferrea & 1 & 33 & 1,30 & 33,33 & 5,56 & 0,14 & 1,95 & 8,80 \\
\hline Total & 77 & 2567 & 100 & 600 & 100 & 7,20 & 100 & 300 \\
\hline
\end{tabular}

Tabela 4 - Parâmetros fitossociológicos para as espécies arbustivo-arbóreas amostradas no gradiente III, na área de Caatinga do Sítio Cigano, Baixio-CE, em ordem decrescente do valor de importância. (NI = número de indivíduos, DA = densidade absoluta, $\mathrm{DR}=$ densidade relativa, $\mathrm{FA}=$ Frequência absoluta, $\mathrm{FR}=$ frequência relativa, $\mathrm{DoA}=$ dominância absoluta, $\mathrm{DoR}=$ dominância relativa, VI = valor de importância).

Table 4 - Phytosociological parameters for woody species sampled in the gradient III area of Sítio Cigano, Baixio-CE, in decreasing order of importance value. $(\mathrm{NI}=$ number of subjects, $\mathrm{DA}=$ absolute density, $\mathrm{DR}=$ relative density, FA $=\mathrm{Absolute}$ frequency, $\mathrm{FR}=$ relative frequency, $\mathrm{DoA}=$ absolute dominance, $\mathrm{DoR}=$ relative dominance, $\mathrm{VI}=$ importance value $)$.

\begin{tabular}{ccccccccc}
\hline Espécies & NI & $\begin{array}{c}\text { DA } \\
(\mathbf{N} / \mathbf{h a})\end{array}$ & $\begin{array}{c}\text { DR } \\
(\boldsymbol{\%})\end{array}$ & $\begin{array}{c}\text { FA } \\
(\boldsymbol{\%})\end{array}$ & $\begin{array}{c}\text { FR } \\
(\boldsymbol{\%})\end{array}$ & $\begin{array}{c}\text { DoA } \\
\left(\mathbf{m}^{2} / \mathbf{h a}\right)\end{array}$ & $\begin{array}{c}\text { DoR } \\
(\boldsymbol{\%})\end{array}$ & VI \\
\hline Poincianella pyramdalis & 16 & 533 & 32,65 & 100 & 14,29 & 5,02 & 42,77 & 89,71 \\
Cochlospermum vitifolium & 4 & 133 & 8,16 & 66,67 & 9,52 & 1,05 & 8,97 & 26,66 \\
Croton sp. & 6 & 200 & 12,24 & 66,67 & 9,52 & 0,42 & 3,57 & 25,34 \\
Bauhinia cheilantha & 6 & 200 & 12,24 & 66,67 & 9,52 & 0,27 & 2,31 & 24,08 \\
Libidibia ferrea & 3 & 100 & 6,12 & 66,67 & 9,52 & 0,63 & 5,39 & 21,04 \\
Aspidormerma cf. pyrifolium & 4 & 133 & 8,16 & 66,67 & 9,52 & 0,36 & 3,08 & 20,77 \\
Comiphora leptophloeos & 1 & 33 & 2,04 & 33,33 & 4,76 & 1,61 & 13,75 & 20,55 \\
Combretum leprosum & 3 & 100 & 6,12 & 66,67 & 9,52 & 0,18 & 1,56 & 17,20 \\
Cordia onconcalix & 2 & 66 & 4,08 & 33,33 & 4,76 & 0,43 & 3,67 & 12,52 \\
Mimosa tenuiflora & 1 & 33 & 2,04 & 33,33 & 4,76 & 0,66 & 5,65 & 12,45 \\
Amburana cearenses & 1 & 33 & 2,04 & 33,33 & 4,76 & 0,64 & 5,43 & 12,23 \\
Pseudobombax marginatum & 1 & 33 & 2,04 & 33,33 & 4,76 & 0,38 & 3,26 & 10,07 \\
Myracrodruon urundeuva & 1 & 33 & 2,04 & 33,33 & 4,76 & 0,07 & 0,58 & 7,38 \\
\hline Total & 49 & 1633 & 100 & 700 & 100 & 11,74 & 100 & 300 \\
\hline
\end{tabular}

De acordo com Queiroz et al. (2006), Poincianella pyramidalis tem sido descrita pela literatura como colonizadora primária em processos sucessionais secundários, sendo a segunda com maior valor de importância descrita por este autor. Bastante comum em estudos em Caatinga, esta espécie foi encontrada, por Pereira et al. (2001), em três áreas com diferentes níveis de perturbação no agreste paraibano e, apresentou alta dominância em um gradiente inicial de sucessão ecológica em ambiente serrano de Caatinga, estudado por 
Carvalho (2010). Para este autor Poincianella pyramidalis é uma das primeiras espécies arbóreas a colonizar áreas de Caatinga em processo de regeneração. A ocorrência desta e de outras espécies secundárias iniciais, nos três gradientes estudados neste trabalho, indicam a existência de uma vegetação secundária, que está se reestabelecendo após a degradação ambiental.

O gradiente II apresentou uma maior abundância de indivíduos e maior densidade total em relação aos outros gradientes. Os gradientes II e III, mais distantes da borda, apresentaram maior riqueza de espécies, demonstrando assim uma heterogeneidade vegetal superior em relação ao gradiente I. A maior riqueza de espécies e famílias foi registrado para o gradiente III, no entanto ocorreu a menor abundância de indivíduos neste gradiente. Maiores valores de frequência e dominância total foram obtidos para o gradiente III. Um número maior de espécies exclusivas também ocorreu para este gradiente.

Assim, verificou-se em áreas próximas a borda uma menor riqueza de espécies e maior abundância de indivíduos, enquanto que em interior de floresta, observou-se maior riqueza de espécies e redução da abundância de indivíduos.

Para Bessa e Medeiros (2011), áreas mais conservadas apresentam menor número de indivíduos devido à grande cobertura do dossel, o que diminui a penetração dos raios solares, consistindo em um ambiente com menos indivíduos e mais árvores frondosas. Embora a área total estudada tenha o mesmo histórico de uso e ocupação, o terceiro gradiente se encontra mais distante da borda e mais próximo de um fragmento de vegetação mais conservado, fato que pode explicar seu estágio mais avançado de sucessão ecológica.

$\mathrm{O}$ gradiente I registrou o maior percentual de indivíduos de espécies pioneiras em relação aos outros gradientes, com este percentual decaindo à medida em que há avanço dos gradientes. Maiores percentuais de indivíduos de espécies secundárias iniciais foram encontrados para os gradientes II e III, no entanto, embora tenha sido registrado um aumento de espécies tardias para o gradiente III, não houve aumento da abundância de indivíduos dessas espécies.

A família Fabaceae foi a que apresentou maior riqueza de espécies para os três gradientes, contribuindo com duas espécies para o gradiente I e cinco espécies para os gradientes II e III. Esta família também foi a mais abundante para os três gradientes, representando 46,9\% dos indivíduos amostrados para o gradiente I, 62,3\% para o gradiente II, $55,1 \%$ para o gradiente III e $55,3 \%$ dos indivíduos amostrados para a área total (Tabelas 2, 3 e 4). Resultado semelhante também foi registrado em outros estudos fitossociológicos, realizados em vegetação ripária de Caatinga (SOUZA e RODAL, 2010; FERRAZ et al., 2013), em gradiente sucessional de depressão sertaneja (CABRAL, 2014), em áreas em regeneração na Caatinga, no agreste paraibano (PEREIRA, et al., 2001; ANDRADE et al., 2007) e no Ceará (BRAGA e CAVALCANTE, 2007), comprovando que esta família é uma das principais em riqueza de espécies e abundância a ocupar diversas tipologias da Caatinga.

O índice de diversidade de Shannon-Wiener $\left(\mathrm{H}^{\prime}\right)$ foi de 2.069 para a área total, valor semelhante a outros trabalhos em vegetação de Caatinga (RODAL et al., 1998; ALCOFORADO-FILHO et al., 2003; AMORIM et al., 2005; FREITAS et al., 2007; DANTAS et al., 2010), os quais variaram de 0,19 a 3,09. Para os gradientes I, II e III estudados este índice foi de 1,$420 ; 1,635$; e 2,159 , respectivamente. Apesar da diversidade total estar dentro da média dos valores encontrados para estudos em áreas de Caatinga, pode-se inferir que a mesma é baixa, uma vez que, poucas espécies concentram a maior parte da dominância. Isso confirma o quanto ações antrópicas interferem na dinâmica das comunidades vegetais, e que o restabelecimento dessas após a perturbação é um processo lento.

A partir do teste de Mann-Whitney ( $<<0,05)$, verificaram-se diferenças significativas de diversidade entre o gradiente I, localizado na borda, e o gradiente III, em interior de floresta. Quanto à similaridade florística entre os três 
ambientes, indicada pelo coeficiente de Jaccard, baseado em uma matriz de presença e ausência das espécies nos diferentes gradientes, registrouse $44 \%$ de similaridade florística entre os gradientes I e II, 50\% entre os gradientes II e III e 38,46\% para os gradientes I e III.

É possível observar que maiores similaridades foram observadas entre gradientes mais próximos, $44 \%$ entre os gradientes I e II; $50 \%$ entre os gradientes II e III; e 38,46\% entre os gradientes I e III, de modo que a dissimilaridade aumentou com a distância entre os gradientes, no entanto estes valores são considerados baixos, uma vez que se trata de uma mesma área, com mesmas condições climáticas e edáficas e mesmo histórico de ocupação.

O número de famílias, gêneros e espécies registrados não apresentou grandes discrepâncias em relação ao encontrado em outros trabalhos de Caatinga em processo de regeneração, considerando as diferenças de amostragem (BESSA e MEDEIROS, 2011; ARAÚJO et al., 2012; CALIXTO JÚNIOR e DRUMOND, 2014). No entanto, o gradiente I apresentou baixa riqueza de espécies o que também foi registrado por Andrade et al. (2005) em uma área degradada na Paraíba e por Conceição (2014) em Caatinga em estágio inicial de sucessão ecológica em Sergipe.

Quanto às densidades, os três gradientes apresentaram valores superiores a outros estudos fitossociológicos, com os mesmos critérios de inclusão, realizados em Caatinga, como o de Silva et al. (2014) que apresentou 1333,3 de densidade total; o de Cabral (2014), desenvolvido em três diferentes gradientes sucessionais de depressão sertaneja, que apresentou densidades de 686, 1090, 1400, respectivamente, para os gradientes de sucessão inicial, intermediário e tardio estudados; e o de Andrade et al. (2005) realizado em área degradada, com outros critérios de inclusão (circunferência à altura da base $\geq 10 \mathrm{~cm}$ ), que obteve 1471 de densidade total. O aumento da densidade de indivíduos pode estar atrelado à alta ocorrência de plantas jovens, demonstrado pelos baixos valores de dominância, observado principalmente nas áreas I e II, o que é comum em ambientes em regeneração. Amorim et al. (2005) destacam que, a densidade está relacionada às características do ambiente, bem como ao seu estado de conservação, assim estes autores concluem que baixas densidades estão associadas a um elevado número de plantas com diâmetros do caule e altura superiores.

Andrade et al. (2005) afirmam que espécies como Myracrodruon urundeuva e Commiphora leptophloeos são mais comumente encontradas em áreas mais protegidas (cercada), ou em matas bem conservadas, e raramente são encontradas em áreas fortemente antropizadas, a frequência destas na área pode caracterizar o início de um restabelecimento da comunidade vegetal.

As espécies mais abundantes em número de indivíduos e com maior valor de importância para os três gradientes foram Croton sp, Bauhinia cheilantha e Poincianella pyramidalis, (Tabelas 1, 2 e 3) respectivamente, desempenhando grande relevância ecológica para a comunidade vegetal na área. Holanda et al. (2015) também registraram a prevalência de uma espécie do gênero Croton para um ambiente de Caatinga em processo de regeneração.

A partir de comparações com dados de outros trabalhos em remanescentes de Caatinga preservada (LEMOS e RODAL, 2002; ANDRADE et al., 2006), pode-se inferir que a área estudada é constituída por uma comunidade de vegetação jovem que ainda apresenta sinais do antropismo, e que as espécies encontradas neste estudo são em sua maioria típicas de ambientes que sofreram algum grau de interferência humana (FREITAS et al., 2007; PEREIRA, 2012; FERRAZ et al., 2014).

Apesar de haver espécies comuns às três áreas, a proporção destas variou ao longo dos gradientes. A espécie Poincianella pyramidalis apresentou um acréscimo do seu valor de importância de acordo com o avanço do interior de floresta, comportando-se assim como uma espécie bastante importante na regeneração, uma vez que ocupa desde ambientes de borda até o interior de floresta.

Os baixos valores de dominância são indícios do antropismo na área, o que resultou em uma 
comunidade que se encontra em estágio de regeneração. A dominância de espécies pioneiras e secundárias iniciais (Croton sp., Myracrodruon urundeuva, Poincianella pyramidalis, Combretum leprosum e Bauhinia cheilantha) para os gradiente I e II, indicam um menor grau de recuperação nestes gradientes em relação ao gradiente III, que apresenta dominância de espécies secundárias iniciais e tardias (Poincianella pyramidalis, Comiphora leptophloeos e Cochlospermum vitifolium). Entretanto, de forma geral, pode-se considerar que na área de estudo a regeneração vem ocorrendo de forma lenta, com predominância das espécies secundárias iniciais.

Diante da intensa degradação antrópica sofrida pela Caatinga, tendo em vista que tal exploração inadequada representa uma ameaça à biodiversidade, associada ao fato desse ecossistema ser pouco conhecido. Estudos que visam compreender como se dá o restabelecimento de ambientes perturbados são de suma importância para o levantamento de informações, que podem vir a ser utilizadas para ações de aceleração na recuperação destes ambientes.

\section{Conclusões}

A formação vegetal estudada se encontra em recuperação, estando em estágio secundário inicial de sucessão ecológica. Os resultados apontam que sua composição florística e estrutura fitossociológica, composta em sua maioria de espécies secundárias iniciais, é resultado da ação antrópica sofrida na mesma, bem como do seu histórico de uso e ocupação.

Os três gradientes estudados variaram quanto à estrutura fitossociológica e composição florística. Constatou-se que, apesar de apresentar o mesmo histórico de uso e ocupação, o reestabelecimento da comunidade em uma mesma área varia em decorrência da distância da borda. A diversidade encontrada na área foi baixa, pois das nove famílias encontradas, oito continham apenas um representante.

\section{Referências}

ALCOFORADO-FILHO, F. G.; SAMPAIO, E. V. S. B.; RODAL, M. J. N. Florística e Fitossociologia de um Remanescente de Vegetação Caducifólia Espinhosa Arbórea em Caruaru, Pernambuco. Acta Botânica Brasileira, Belo Horizonte, v. 17, n. 2, p. 287-303. 2003.

AMORIM, I. L.; SAMPAIO, E. V. S. B.; ARAÚJO, E. L. Flora e Estrutura da Vegetação Arbustivo-arbórea de uma Área de Caatinga do Seridó, RN, Brasil. Acta Botânica Brasileira, Belo Horizonte, v. 19, n. 3, p. 615-623, 2005.

ANDRADE, L. A. et al. Análise Florística e Estrutural de Matas Ciliares Ocorrentes em Brejo de Altitude no Município de Areia, Paraíba. Revista Brasileira de Ciências Agrárias, Recife-PE, v. 1, p. 31-40, out./dez. 2006.

ANDRADE, L. A. et al. Análise da Vegetação Sucessional em Campos Abandonados no Agreste Paraibano. Revista Brasileira de Ciências Agrárias, Recife-PE, v. 2, n. 2, p. 135142, abr./Jun. 2007.

ANDRADE, L. A. et al. Analise da Cobertura de duas Fitofisionomias de Caatinga, com Diferentes Históricos de Uso, no Município de São João do Cariri, Estado da Paraíba. Cerne, Lavras, v. 11, n. 3, p. 253-262, jul./set. 2005.

ARAÚJO, B. A. et al. Estrutura Fitossociológica em uma área de Caatinga no Seridó Paraibano. Revista Educação Agrícola Superior, Brasília, V. 27, n. 1, p. 25-29, 2012.

AYRES, M. et al. Bioestat 5.3: Aplicações estatísticas nas Áreas das Ciências Biológicas e Médicas. Belém-PA: Publicações avulsas do Mamirauá, 2007.

BESSA, M. A. P.; MEDEIROS, J. F. Levantamento Florístico e Fitossociológico em Fragmentos de Caatinga no Município de Taboleiro Grande-RN. GEO Temas, Pau dos Ferros - RN, v. 1, n. 2, p. 69-83, jul./dez. 2011. 
BRAGA, E. P.; CAVAlCANTE, A. M. B. Florística e Fitossociologia de um Fragmento de Caatinga Arbórea em Regeneração no Ceará. In: Congresso de Ecologia do Brasil, 8, 2007, Caxambu - MG. Anais... Caxambu: Sociedade de Ecologia do Brasil, 2007.

CABRAL, G. A. L. Fitossociologia em diferentes estádios sucessionais de Caatinga Santa Terezinha- PB. 2014. 138 f. Dissertação (Mestrado em Biologia Vegetal) - Universidade Federal do Pernambuco, Recife-PE, 2014.

CABRAL, G. A. L.; SAMPAIO, E. V. S. B.; ALMEIDA-CORTEZ, J. S. Estrutura Espacial e Biomassa da Parte Aérea em Diferentes Estádios Sucessionais de Caatinga, em Santa Terezinha, Paraíba. Revista Brasileira de Geografia Física, Recife, v. 6, n. 3, p 566-574, 2013.

CALIXTO JUNIOR, J. T.; DRUMOND, M. A. Estrutura fitossociológica de um fragmento de Caatinga sensu stricto 30 anos após corte raso, Petrolina-PE, Brasil. Revista Caatinga, Mossoró, v. 24, n. 2, p. 67-74, abr./jun. 2011.

CALIXTO JUNIOR, J. T.; DRUMOND, M. A. Estudo comparativo da estrutura fitossociológica de dois fragmentos de Caatinga em níveis diferentes de conservação. Pesquisa Florestal Brasileira, Colombo, v. 34, n. 80, p. 345-355, out./dez. 2014.

CARVALHO, E. C. D. Estrutura e Estágios de Sucessão Ecológica da vegetação de caatinga em ambiente serrano no Cariri paraibano. 2010. 68 f. Dissertação (Mestrado em Ciência e Tecnologia Ambiental) - Universidade Estadual da Paraíba, Campina Grande-PB, 2010.

CARVALHO, E. C. D.; SOUZA, B. C.; TROVÃO, D. M. B. M. Ecological succession in two remnants of the Caatinga in the semi-arid tropics of Brazil. Revista brasileira de Biociências, Porto Alegre, v. 10, n. 1, p. 13-19, jan./mar. 2012.
CONCEIÇÃO, G. G. Diversidade e Composição da Vegetação ao Longo de um Gradiente Sucessional na Caatinga. 2014. 81 f. Dissertação (Mestrado em Ecologia e Conservação) Universidade Federal de Sergipe, São CristóvãoSE, 2014.

DANTAS, J. G. et al. Estrutura do Componente Arbustivo/Arbóreo de uma Área de Caatinga Situada no Município De Pombal-PB. Revista Verde, Mossoró - RN, v.5, n.1, p. $134-142$ jan./mar. de 2010.

DRUMOND, M. et al. Estratégias para o uso sustentável da biodiversidade da caatinga. In: Seminário para avaliação e identificação de ações prioritárias para a conservação, utilização sustentável e repartição de benefícios da biodiversidade do bioma Caatinga, 2000. Anais... Petrolina-PE: EMBRAPA/CPATSA, UFPE e Conservation International do Brasil, Petrolina, 2000.

EMBRAPA. Centro Nacional de Pesquisa de Solos. Sistema Brasileiro de Classificação de Solos. 2. Ed. Rio de Janeiro: EMBRAPA-SPI, 2006. 306 p.

FABRICANTE, J. R.; ANDRADE, L. A. Análise Estrutural de um Remanescente de Caatinga no Seridó Paraibano. O ecologia Brasiliensis, Rio de janeiro, v. 11, n. 3, p. 341349, 2007.

FERRAZ, J. S. F. et al. Estrutura do Componente Arbustivo-Arbóreo da Vegetação em duas Áreas De Caatinga, no Município de Floresta, Pernambuco. Revista Árvore, ViçosaMG, v.38, n.6, p.1055-1064, 2014.

FERRAZ, R. C. et al. Levantamento Fitossociológico em Área de Caatinga no Monumento Natural Grota Do Angico, Sergipe, Brasil. Revista Caatinga, Mossoró, v. 26, n. 3, p. 89 - 98, jul./set., 2013.

FREITAS, R. A. C. et al. Estudo Florístico e Fitossociológico do Extrato Arbustivo-Arbóreo 
de dois Ambientes Em Messias Targino Divisa RN/PB. Revista Verde, Mossoró - RN, v.2, n.1, p. 135-147, Jan./Jul. 2007.

FREITAS, W. K. e MAGALHÃES, L. M. S. Métodos e Parâmetros para Estudo da Vegetação com Ênfase no Estrato Arbóreo. Floresta e Ambiente, Rio de janeiro, v. 19, n.4, p.520-540, 2012.

GANDOLFI, S.; LEITÃO FILHO, H.; BEZERRA, C. L. F. Levantamento florístico e caráter sucessional das espécies arbustivoarbóreas de uma floresta mesófila semidecídua no município de Guarulhos-SP. Revista Brasileira de Botânica, Rio de Janeiro, v. 55, n. 4, p.753-767, out./dez., 1995

GIULIETTI, A. M. et al. Diagnóstico da vegetação nativa do bioma caatinga. In: SILVA, J. M. C. et al. Biodiversidade da Caatinga: áreas e ações prioritárias para a conservação. BrasíliaDF: Ministério do Meio Ambiente: Universidade Federal de Pernambuco, 2003. p.47-78.

HOLANDA, A. C. et al. Estrutura da vegetação em remanescentes de caatinga com diferentes históricos de perturbação em Cajazeirinhas (PB). Revista Caatinga, Mossoró, v. 28, n. 4, p. 142 150, out./dez., 2015.

IPECE. Perfil Básico municipal 2014 Baixio. Disponível em: <http://www.ipece.ce.gov.br/publicacoes/perfil _basico/pbm-2014/Baixio.pdf.> Acesso em 25 de Março de 2016.

LEMOS, J. R.; RODAL, M. J. N. Fitossociologia Do Componente Lenhoso de um Trecho Da Vegetação de Caatinga no Parque Nacional Serra da Capivara, Piauí, Brasil. Acta Botânica Brasileira, Belo horizonte, v. 16, n. 1, p. 23-42, 2002.

MARANGON, G. P. et al. Estrutura e Padrão Espacial da Vegetação em Uma Área de Caatinga. Floresta, Curitiba, PR, v. 43, n. 1, p.
83-92, jan./mar. 2013.

NASCIMENTO, C. E. S. Estudo florístico e Fitossociológico de um Remanescente de Caatinga à Margem do Rio São Francisco. 1998. 84 f. Dissertação (Mestrado em Botânica) Universidade Federal do Pernambuco, RecifePE, 1998.

PEREIRA, E. A. A. Estrutura Fitossociológica e Composição Mineral de Espécies Lenhosas de um Fragmento de Caatinga no Semiárido Paraibano. 2012. 74 f. Dissertação (Mestrado em Ciências Florestais), Universidade Federal de Campina Grande, Campina Grande- PB, 2012.

PEREIRA, I. M. et al. Regeneração natural em um remanescente de Caatinga sob diferentes níveis de perturbação, no Agreste Paraibano. Acta Botânica Brasileira, Belo Horizonte, v.15, n. 3, p. 413-426, 2001.

QUEIROZ, J. A. et al. Análise da Estrutura Fitossociológica da Serra do Monte, Boqueirão, Paraíba. Revista de Biologia e Ciências da Terra, Campina Grande, v. 6, n. 1, p. 251-259, 2006.

RAMBALDI, D. M.; OLIVEIRA, D. A. S. Fragmentação de Ecossistemas: Causas, efeitos sobre a biodiversidade e recomendações de políticas públicas. Brasília: MMA/SBF, 2003. $510 \mathrm{p}$.

RODAL, M. J. N. Fitossociologia da vegetação Arbustivo-arbórea em quatro áreas de Caatinga em Pernambuco. 1992. 241 f. Tese (Doutorado em Ciências) - Universidade Estadual de Campinas. Campinas-SP, 1992.

RODAL, M. J. N. et al. Fitossociologia do Componente Lenhoso de um Refúgio Vegetacional no Município De Buíque, Pernambuco. Revista Brasileira de Biologia, São Carlos-SP, v. 58, n. 3, p. 517-526, 1998.

RODAL, M. J. N.; NASCIMENTO, L. M. Levantamento Florístico da Floresta Serrana da Reserva Biológica De Serra Negra, Microrregião 
de Itaparica, Pernambuco, Brasil. Acta Botânica Brasileira, Belo Horizonte, v. 16, n. 4, p. 481500, 2002.

RODAL, M. J. N.; SAMPAIO, E. V. S. B.; FIGUEIREDO, M. A. Manual Sobre Estudos Florístico e Fitossociológico: Ecossistema Caatinga. Brasília: Sociedade Botânica do Brasil, 2013.

SANTANA, J. A. da S.; SOUTO, J. S. Diversidade e Estrutura Fitossociológica da Caatinga na Estação Ecológica do Seridó-RN. Revista de Biologia e Ciências da Terra, Campina Grande, v. 6, n. 2, p. 232-242, 2006.

SHEPHERD, G. J. FITOPAC 2: Manual do Usuário. Campinas: Departamento de Botânica. IB da UNICAMP, 1995. 93 p.

SILVA, S. O. et al. Regeneração Natural em um Remanescente de Caatinga com Diferentes Históricos de Uso no Agreste Pernambucano. Revista Árvore, Viçosa-MG, v.36, n.3, p.441450, 2012.

SILVA, V. M. A.; ALMEIDA, C. A.; ARAÚJO, S. M. S. Fitossociologia na área de proteção ambiental do cariri paraibano, Boa Vista - PB. In: Congresso Nacional de Meio Ambiente de Poços De Caldas, 11, 2014, Poços de Caldas MG. Anais... Poços de Caldas: Congresso Nacional de Poços de Caldas, 2014.

SOUZA, J. A. N.; RODAL, M J. N. Levantamento Florístico em Trecho de Vegetação Ripária de Caatinga no Rio Pajeú, Floresta/Pernambuco-Brasil. Revista Caatinga, Mossoró, v. 23, n. 4, p. 54-62, out./dez. 2010.

TABARELli, M.; SILVA, J. M. C. Áreas e ações prioritárias para a conservação da biodiversidade da Caatinga. In: LEAL, I. R.; TABARELLI, M.; SILVA, J. M. C. Ecologia e Conservação da Caatinga. Recife: Ed. Universitária da UFPE, 2003. p. 777-796.
Conhecimento sobre plantas lenhosas da Caatinga: lacunas geográficas e ecológicas. In: SILVA, J. M. C. et al. Biodiversidade da caatinga: áreas e ações prioritárias para a conservação. Brasília, DF: Ministério do Meio Ambiente, Universidade Federal de Pernambuco, 2003. p. 101-111.ores. 2011, p. 273-286.

TABARELLI, M.; VICENTE, A. 